\title{
International consensus definitions of video signs of concussion in professional sports
}

\author{
Gavin A Davis, ${ }^{\oplus 1,2}$ Michael Makdissi, ${ }^{1,3}$ Paul Bloomfield, ${ }^{4}$ Patrick Clifton, ${ }^{5}$ \\ Ruben J Echemendia, ${ }^{\oplus 6}$ Éanna Cian Falvey, ${ }^{7}$ Gordon Ward Fuller, ${ }^{\circledR 8}$ Gary Green, $^{9}$ \\ Peter Harcourt, ${ }^{5}$ Thomas Hill, $^{10}$ Nathan McGuirk, ${ }^{11}$ Willem Meeuwisse, ${ }^{12}$ \\ John Orchard, ${ }_{13}^{13}$ Martin Raftery, ${ }^{7}$ Allen K Sills, ${ }^{14}$ Gary S Solomon, ${ }^{14}$ Alex Valadka, ${ }^{9}$ \\ Paul McCrory ${ }^{15}$
}

- Additional material is published online only. To view please visit the journal online (http://dx.doi.org/10.1136/ bjsports-2019-100628).

For numbered affiliations see end of article.

\section{Correspondence to} Professor Gavin A Davis, Suite 53 - Neurosurgery, Cabrini Malvern, Wattletree Road, Malvern, Victoria 3144, Australia; gavin.davis@me.com

GAD and MM are joint first authors.

Received 24 January 2019 Revised 19 March 2019 Accepted 20 March 2019 Published Online First 6 April 2019
Check for updates

(C) Author(s) (or their employer(s)) 2019. No commercial re-use. See rights and permissions. Published by BMJ.

To cite: Davis GA Makdissi M, Bloomfield P et al. Br J Sports Med 2019:53:1264-1267.

\begin{abstract}
Background The use of video to assist professional sporting bodies with the diagnosis of sport-related concussion (SRC) has been well established; however, there has been little consistency across sporting codes with regards to which video signs should be used, and the definitions of each of these signs.
\end{abstract}

Aim The aims of this study were to develop a consensus for the video signs considered to be most useful in the identification of a possible SRC and to develop a consensus definition for each of these video signs across the sporting codes.

Methods A brief questionnaire was used to assess which video signs were considered to be most useful in the identification of a possible concussion. Consensus was defined as $>90 \%$ agreement by respondents. Existing definitions of these video signs from individual sports were collated, and individual components of the definitions were assessed and ranked. A modified Delphi approach was then used to create a consensus definition for each of the video signs.

Results Respondents representing seven sporting bodies (Australian Football League, Cricket Australia, Major League Baseball, NFL, NHL, National Rugby League, World Rugby) reached consensus on eight video signs of concussion. Thirteen representatives from the seven professional sports ranked the definition components. Consolidation and refinement of the video signs and their definitions resulted in consensus definitions for six video signs of possible concussion: lying motionless, motor incoordination, impact seizure, tonic posturing, no protective action-floppy and blank/ vacant look.

Conclusions These video signs and definitions have reached international consensus, are indicated for use by professional sporting bodies and will form the basis for further collaborative research.

\section{INTRODUCTION}

The diagnosis and management of sport-related concussion (SRC) has evolved substantially over recent decades, with international collaboration enhancing research efforts. ${ }^{1}$

The identification of possible concussive injuries is not always readily apparent from the sidelines, often despite having experienced medical staff available. The use of video technology has been adopted by many professional sports to assist with the detection of possible concussive injuries. ${ }^{2-15}$ In

\section{What are the new findings?}

- Video review has rapidly become an important tool in professional sports for the identification of brief early signs of a possible concussion. Currently, however, there is little consistency across sporting codes regarding the definition and interpretation of the video signs.

- Expert members from seven national and international sporting codes agreed on the inclusion of six signs for the identification of a possible concussion: lying motionless, motor incoordination, impact seizure, tonic posturing, no protective action-floppy and blank/vacant look.

- Consensus definitions were developed for all six video signs.

How might it impact on clinical practice in the future?

- Video review can assist sideline physicians in identifying possible concussions which may otherwise not be detected.

- Consistent definitions of video signs of possible concussion across sporting codes will facilitate further research on the reliability of video signs in the diagnosis of concussion, and allow a determination of which signs (if any) should mandate permanent removal from play.

a previous study, the authors examined the use of video review in a number of national and international professional sports. ${ }^{16}$ Signs that were found to be common to most international professional sports included lying motionless/loss of responsiveness and motor incoordination. The video signs considered by the majority of sports as most predictive of a diagnosis of SRC included motor incoordination, impact seizure, tonic posturing and lying motionless. ${ }^{16}$ There was no universal consensus however as to the definitions of each of the video signs or how they should be interpreted (ie, which video sign mandated permanent removal from play). Currently, there is minimal evidence on the positive and negative predictive value of the video signs of SRC to guide management decisions. 
A consensus of terminology and definitions is critical to inform each sporting body on the appropriate use of video technology as an aid to the management of SRC, and to advance the scientific research to address a number of outstanding questions, such as predictive value of video signs for the diagnosis of SRC, and the potential use of these data to assist the sporting codes with management and prevention strategies.

The aims of this study were to develop a consensus for the video signs considered to be most useful in the identification of a possible SRC and to develop a consensus definition for each of these video signs across the sporting codes.

\section{METHODS}

Senior medical advisers and chief medical officers from major international sporting codes, including the Australian Football League (AFL), Cricket Australia (CA), Major League Baseball (MLB), NFL, NHL, National Rugby League (NRL) and World Rugby (WR), participated in the previous study, ${ }^{16}$ and were purposively sampled and invited to participate in this study.

In the previous study, ${ }^{16} 17$ different video signs of possible concussion were identified as currently being used by international professional sports. These include:

- Lying motionless.

- Motor incoordination/ataxia/staggering gait/stumbles/stagger.

- No protective action-floppy.

- No protective action-tonic.

- Cervical hypotonia.

- Uncontrolled fall to ground.

- Controlled fall.

- Impact seizure/convulsion.

- Tonic posturing.

- Blank/vacant look.

- Dazed.

- Slow to get up.

- Clutching at head.

- Walking away from pitch disengaged with game.

- Disorientation.

- Confusion/behaviour change.

Lying motionless

Motor incoordination
Impact seizure

Tonic posturing
Facial injury/fracture.

A brief questionnaire was developed and sent out to participants in the current study to assess which video signs were considered to be most useful in the identification of a possible concussion. Consensus was defined as $>90 \%$ agreement by respondents.

For video signs that reached $>90 \%$ agreement, existing definitions were obtained from each of the participating sports and a qualitative analysis was performed by two experienced clinicians (GAD, MM). Individual components of each definition were categorised as either (1) reaching or (2) failing to reach consistency across the professional sports. A modified Delphi approach was then used to create consensus definitions for each of the video signs. At each stage, respondents from all sports were invited to provide additional comments or suggestions for improving the definitions.

\section{RESULTS}

Eleven representatives from six different sports (AFL, CA, MLB, NFL, NRL, WR) responded quantitatively, and two representatives from one sport (NHL) responded qualitatively to the initial questionnaire.

The results are summarised in online supplementary file 1 .

Video signs with $>90 \%$ agreement were:

- Lying motionless.

- Motor incoordination/ataxia/staggering gait/stumbles/stagger.

- No protective action-floppy.

- No protective action-tonic.

- Cervical hypotonia.

- Impact seizure/convulsion.

- Tonic posturing.

- Blank/vacant look.

Thirteen representatives from seven professional sports (AFL, CA, MLB, NFL, NHL, NRL, WR) were involved in the modified Delphi approach resulting in a consensus definition for each of the video signs.

The final consensus definitions of the video signs of possible concussion are detailed in the table.

Lying without purposeful movement on the playing surface, for $>2 \mathrm{~s}^{*}$. Does not appear to move or react purposefully, respond or reply appropriately to the game situation (including teammates, opponents, umpires or medical staff). Concern may be shown by other players or match officials $\left({ }^{*}>2 \mathrm{~s}\right.$ for removal and assessment of the athlete. Significantly longer periods of lying motionless may necessitate immediate and permanent removal from play, depending on the circumstances) Appears unsteady on feet (including losing balance, staggering/stumbling, struggling to get up, falling) or in the upper limbs (including fumbling). May occur in rising from the playing surface or in the motion of walking/running/skating

Involuntary clonic movements that comprise periods of asymmetric and irregular rhythmic jerking of axial or limb muscles

Involuntary sustained contraction of one or more limbs (typically upper limbs), so that the limb is held stiff despite the influence of gravity or the position of the player. The tonic posturing could involve other muscles such as the cervical, axial and lower limb muscles. Tonic posturing may be observed while the athlete is on the playing surface or in the motion of falling, where the player may also demonstrate no protective action*

( ${ }^{*}$ This was previously known as no protective action - stiff)

Falls to the playing surface in an unprotected manner (ie, without stretching out hands or arms to lessen or minimise the fall) after direct or indirect contact to the head. The player demonstrates loss of motor tone (which may be observed in the limbs and/or neck* ${ }^{*}$ before landing on the playing surface

(*When the player's arms are being held by a tackling opponent, this may only be observed in the neck, which was previously known as cervical hypotonia)

Blank/vacant look 


\section{DISCUSSION}

The use of video technology to assist with the diagnosis of possible concussion has been widely adopted by international professional sports ${ }^{1-3} 5-15$; ; however, the variability in the video signs used and their definition has resulted in some confusion when comparing methods and results across the different sports. Common terminology and definitions are crucial to advance scientific and collaborative research, with the ultimate objective of improving game-day management of SRC.

The current study has identified six video signs that are considered to be most useful in the identification of a possible concussion. While there are other video signs that also occur following possible concussive injuries, these are considered non-specific (eg, facial injury, clutching at head) or too difficult to objectively assess on video (eg, confusion, behaviour change). As such, the six video signs defined in this study are considered by the representatives of seven national and international professional sporting bodies to be the most useful signs of a possible concussion that can be assessed using current video technology. The presence of any one sign does not necessarily indicate that concussion has occurred, but rather, the presence of any of these signs indicates the need to remove the athlete from the playing arena for formal assessment and evaluation from a suitably qualified health practitioner.

\section{Lying motionless}

The duration of lying motionless has been arbitrarily defined as $>2$ s. There was unanimous agreement that duration $\leq 1 \mathrm{~s}$ was too short, and that the ideal definition falls between 2 and 5 s. Some sporting codes have previously stipulated that lying motionless $>5$ s mandates permanent removal from play, but, in the absence of supporting evidence for this recommendation, the authors' consensus opinion is that $>2 \mathrm{~s}$ is the appropriate duration to mandate assessment, although it is acknowledged that future research is required to confirm the optimum cut-off.

\section{Motor incoordination}

Earlier definitions of motor incoordination have incorporated several synonyms of unsteadiness. The current definition has included the most commonly used and appropriate terms, and overcomes the problems of separate definitions for incoordination in the process of attempting to rise from one's feet, and in the process of motion across the playing surface by combining both into a convenient, simplified definition.

\section{Impact seizure}

The current International League Against Epilepsy (ILAE) definition of a seizure is "a transient occurrence of signs and/or symptoms due to abnormal excessive or synchronous neuronal activity in the brain", ${ }^{18}$ but this is impractical for use in video assessment of sports concussion. The proposed definition is consistent with earlier definitions of impact seizures ${ }^{17}$; however, the term impact seizure is preferred over "impact convulsion" in keeping with the 2017 ILAE classification. ${ }^{18}$

\section{Tonic posturing}

The definition of tonic posturing for the athlete lying on the playing surface is consistent with previous definitions. ${ }^{17}$ However, in the process of a concussive injury when the athlete is upright (often a clash while jumping in the air), the athlete may fall to the playing surface unresponsive, and traditionally many have referred to this as 'ragdoll'. However, if the athlete has tonic posturing as they fall, then they are not 'floppy' like a ragdoll, but 'stiff' due to tonic posturing. To clarify this distinction, no protective action-stiff has been incorporated into the definition of tonic posturing.

\section{No protective action-floppy}

This definition is of the video sign that some refer to as 'ragdoll'. However, in some circumstances, the athlete's arms are held tightly to the torso by a tackling opponent, and as the athlete and opponent fall to the ground, there is no opportunity for the athlete to place the arms out to protect themselves from the fall. In this circumstance, if the athlete is 'floppy', then the only evidence for this on video may be observed in the neck-that is, cervical hypotonia. Given that cervical hypotonia is a form of no protective action-floppy, it has been incorporated in the definition as such.

\section{Blank/vacant look}

This video sign is difficult to define because, in part, it requires an appreciation of the athlete's normal facial appearance and expressions. This is often best appreciated by the team doctor or trainer, and, in sports with helmets with face masks, there may be no clear view of the face and eyes to adequately assess for this video sign. Nevertheless, in sports in which the video clearly provides the observer with a view of the face, this definition is considered appropriate and valid. ${ }^{10}$

\section{Limitations}

This study is a consensus study performed by representatives from international professional sporting codes. Most of the original studies of video signs in these sports were conducted among professional male athletes, ${ }^{2-15} 18$ and therefore, application of these video signs to females and amateur athletes requires validation. While many of the data that formed the basis for these definitions were acquired in individual sports, and reached good levels of validity and reliability, no study has yet validated the current definitions across multiple sporting codes, and further research is required to determine the reliability of these definitions when used by observers of different backgrounds, including medical practitioners, certified athletic trainers and allied health personnel.

\section{CONCLUSION}

This consensus study provides a practical list of video signs of concussion in sport and, importantly, provides operational definitions for each of these video signs. These definitions and video signs are suitable for use in all sporting codes; however, the predictive value of each sign, or groups of signs, remains to be determined and will form the basis of further research.

\footnotetext{
Author affiliations

${ }^{1}$ Florey Institute of Neuroscience and Mental Health-Austin Campus, Heidelberg,

Victoria, Australia

${ }^{2}$ Neurosurgery, Cabrini Hospital, Malvern, Victoria, Australia

${ }^{3}$ La Trobe Sport and Exercise Medicine Research Centre, Melbourne, Victoria, Australia

${ }^{4}$ National Rugby League (NRL), Sydney, New South Wales, Australia

${ }^{5}$ Australian Football League, Melbourne, Victoria, Australia

${ }^{6}$ National Hockey League, Philadelphia, Pennsylvania, USA

${ }^{7}$ World Rugby, Dublin, Ireland

${ }^{8}$ School of Health and Related Research, University of Sheffield, Sheffield, UK

${ }^{9}$ Major League Baseball, New York, New York, USA

${ }^{10}$ Cricket Australia, Melbourne, Victoria, Australia

${ }^{11}$ National Rugby League, Sydney, New South Wales, Australia

${ }^{12}$ National Hockey League, Calgary, Alberta, Canada

${ }^{13}$ Cricket Australia, Sydney, New South Wales, Australia

${ }^{14}$ National Football League, New York, New York, USA
} 
${ }^{15}$ Melbourne Brain Centre, Florey Institute of Neuroscience and Mental HealthAustin Campus, Heidelberg, Victoria, Australia

Contributors GAD and MM contributed to the conception of the work. All authors contributed to the acquisition, analysis or interpretation of data, drafting the work or revising it critically for important intellectual content, final approval of the version published and agreement to be accountable for all aspects of the work.

Funding The authors have not declared a specific grant for this research from any funding agency in the public, commercial or not-for-profit sectors.

Competing interests GAD is an Honorary member of the Australian Football League (AFL) Concussion Working Group. MM is an Honorary member of the AFL Concussion Working Group. PB is Chief Medical Officer of National Rugby League (NRL). PC is Head of Health, Safety and Laws, AFL. RJE is Co-Chair, National Hockey League (NHL)/NHL Players Association Concussion Subcommittee and Chair of the MLS Concussion Committee. ECF is Member of World Rugby concussion working group. GWF is Member of World Rugby concussion working group. GG is Medical Director, Major League Baseball. PH is AFL Medical Director. TH is State Medical Officer, Cricket Australia. NM is General Manager, Competitions and Operations, Football, NRL. WM is NHL Medical Director. JO is Chief Medical Officer, Cricket Australia. MR is Chief Medical Officer, World Rugby. AKS is Chief Medical Officer, National Football League (NFL). GSS is Senior Advisor, NFL Department of Health and Safety. AV is a consultant for Mild Traumatic Brain Injury, Major League Baseball. PM is an Honorary member of the AFL Concussion Working Group. ICJME disclosure forms have been provided.

Patient consent for publication Not required.

Ethics approval As this study does not contain any patient data, research ethics committee approval was not required.

Provenance and peer review Not commissioned; externally peer reviewed.

\section{REFERENCES}

1 McCrory P, Meeuwisse W, Dvořák J, et al. Consensus statement on concussion in sport-the $5^{\text {th }}$ international conference on concussion in sport held in Berlin, October 2016. Br J Sports Med 2017;51:838-87.

2 Davis G, Makdissi M. Use of video to facilitate sideline concussion diagnosis and management decision-making. J Sci Med Sport 2016;19:898-902.
3 Fuller GW, Kemp SPT, Raftery M. The accuracy and reproducibility of video assessment in the pitch-side management of concussion in elite rugby. J Sci Med Sport 2017;20:246-9.

4 Gardner AJ, Howell DR, Iverson GL. A video review of multiple concussion signs in National Rugby League match play. Sports Med Open 2018;4.

5 Gardner AJ, Howell DR, Levi CR, et al. Evidence of concussion signs in National Rugby League match play: a video review and validation study. Sports Med Open 2017;3.

6 Gardner AJ, Kohler RMN, Levi CR, et al. Usefulness of video review of possible concussions in National Youth Rugby League. Int J Sports Med 2017;38:71-5.

7 Gardner AJ, Wojtowicz M, Terry DP, et al. Video and clinical screening of National Rugby League players suspected of sustaining concussion. Brain Inj 2017;31:1918-24.

8 Hutchison MG, Comper P, Meeuwisse WH, et al. A systematic video analysis of National Hockey League (NHL) concussions, part I: who, when, where and what? $\mathrm{Br} J$ Sports Med 2015:49:547-51.

9 Hutchison MG, Comper P, Meeuwisse WH, et al. A systematic video analysis of National Hockey League (NHL) concussions, part II: how concussions occur in the NHL. Br J Sports Med 2015;49:552-5.

10 Makdissi M, Davis G. The reliability and validity of video analysis for the assessment of the clinical signs of concussion in Australian football. J Sci Med Sport 2016;19:859-63.

11 Tucker R, Raftery M, Kemp S, et al. Risk factors for head injury events in professional rugby union: a video analysis of 464 head injury events to inform proposed injury prevention strategies. Br J Sports Med 2017:51:1152-7.

12 Makdissi M, Davis G. Using video analysis for concussion surveillance in Australian football. J Sci Med Sport 2016;19:958-63.

13 Cross MJ, Tucker R, Raftery M, et al. Tackling concussion in professional rugby Union: a case-control study of tackle-based risk factors and recommendations for primary prevention. Br J Sports Med 2019;53:1021-5.

14 Bruce JM, Echemendia RJ, Meeuwisse W, et al. Development of a risk prediction model among professional hockey players with visible signs of concussion. Br J Sports Med 2018;52:1143-8.

15 Echemendia RJ, Bruce JM, Meeuwisse W, et al. Can visible signs predict concussion diagnosis in the National Hockey League? Br J Sports Med 2018;52:1149-54.

16 Davis GA, Makdissi M, Bloomfield $\mathrm{P}$, et al. International study of video review of concussion in professional sports. Br J Sports Med 2019;53:1298-303.

17 McCrory PR, Berkovic SF. Video analysis of acute motor and convulsive manifestations in sport-related concussion. Neurology 2000;54:1488-91.

18 Fisher RS, Cross JH, French JA, et al. Operational classification of seizure types by the International League Against Epilepsy: position paper of the ILAE Commission for classification and terminology. Epilepsia 2017;58:522-30. 